\title{
Emotion
}

\section{Affective States Contribute to Trait Reports of Affective Well-Being}

Annette Brose, Ulman Lindenberger, and Florian Schmiedek

Online First Publication, April 29, 2013. doi: 10.1037/a0032401

CITATION

Brose, A., Lindenberger, U., \& Schmiedek, F. (2013, April 29). Affective States Contribute to Trait Reports of Affective Well-Being. Emotion. Advance online publication. doi:

$10.1037 / a 0032401$ 


\title{
Affective States Contribute to Trait Reports of Affective Well-Being
}

\author{
Annette Brose and Ulman Lindenberger \\ Max Planck Institute for Human Development, Berlin, Germany
}

\author{
Florian Schmiedek \\ Max Planck Institute for Human Development, Berlin, Germany \\ and German Institute for International Educational Research, \\ Frankfurt/Main, Germany
}

\begin{abstract}
Asking people to provide global judgments, or trait reports, of their affective experience is a standard method for assessing trait affective well-being, with countless applications in the social sciences. Trait reports reflect numerous influences that generally go unnoticed. Although state affect is a highly plausible candidate for such influences, this source of unwanted variance does not receive much attention and is usually not controlled for in empirical studies. Using 100-day data from the COGITO study, we provide direct and strong evidence that trait reports of affect depend on how people feel at the time they provide the evaluations (i.e., their affective state). For example, participants experiencing more positive affect on a specific day relative to their individual mean also provide more positive ratings of their global affective experience. Furthermore, we found that current affect influences trait ratings in a surprisingly differentiated way - those particular facets of affect that are more/less prevalent at a certain moment are believed to occur more/less often in general. We stress the need for repeated observations within individuals to estimate state contributions to standard assessments of trait affect, to distinguish between state and trait in psychological assessment, and to achieve good indicators of affective experiences in the social and medical sciences.
\end{abstract}

Keywords: trait and state affect, self-report bias, feelings-as-information, mood-congruent judgments

Asking people about their affective experiences has countless applications in the social sciences. In policy evaluations, for example, economists and sociologists study affective experiences (Stone, Schwartz, Broderick, \& Deaton, 2010). Affective experiences also matter because they are linked to psychopathology (Clark \& Watson, 1991), personality (Gross, Sutton, \& Ketelaar, 1998), and stress (Lazarus, 1999). Furthermore, psychologists examine the nature of the basic dimensions of affect (Carroll, Yik, Russell, \& Barrett, 1999). Some of this research is concerned with stable individual differences in affect (i.e., traits), others with states that reflect how a person feels at a given moment. Here we provide direct and strong evidence that the distinction between measures of state and trait affect is blurred when single-occasion state and trait reports of affect are used. This is in accordance with

Annette Brose and Ulman Lindenberger, Center for Lifespan Psychology, Max Planck Institute for Human Development, Berlin, Germany; Florian Schmiedek, Center for Lifespan Psychology, Max Planck Institute for Human Development, Berlin, Germany and German Institute for International Educational Research, Frankfurt/Main, Germany.

The COGITO Study was supported by the Max Planck Society, including a grant from the Max Planck Society's innovation fund (M.FE.A.BILD0005); the Alexander von Humboldt Foundation's Sofja Kovalevskaja Award (to Martin Lövdén) donated by the German Federal Ministry for Education and Research (BMBF); the German Research Foundation (DFG; KFG 163); and the BMBF (CAI). We thank Norbert Schwarz and Michael Eid for helpful comments on earlier versions of this article and Julia Delius for editorial assistance.

Correspondence concerning this article should be addressed to Annette Brose, Max Planck Institute for Human Development, Lentzeallee 94, 14195 Berlin, Germany. E-mail: brose@mpib-berlin.mpg.de theoretical expectations and some prior empirical evidence that have had surprisingly little impact, as single-occasion trait reports continue to be the norm. Our findings have implications for all research traditions mentioned above.

Trait-level affect is often obtained on single occasions with items such as, "How happy were you during the last year?" Such trait reports do not deliver accurate estimates of actual experiences as experiential information is no longer present in memory and inferences guided by information from episodic and semantic memory are required (Robinson \& Clore, 2002; Schwarz, 2007). In fact, the construction of trait affect is influenced by beliefs about one's emotions and ideal affect (Barrett, 1997; Ross, 1989; Scollon, Howard, Caldwell, \& Ito, 2009), by particular moments of emotional episodes (e.g., the peak and the end of an emotional episode; Fredrickson, 2000), and by the motivation to keep unwanted material out of consciousness (e.g., anxiety provoking thoughts; Wilson \& Dunn, 2004).

Reports of current state affect, instead, attenuate memory biases and represent actual experiences (Robinson \& Clore, 2002). Yet state and trait affect capture aspects of each other and, therefore, their measures are, to some extent, confounded. On the one hand, state affect is predictable by traits that determine the propensity of affect occurrence (i.e., neuroticism; Watson \& Clark, 1984). Likewise, stable beliefs may influence state affect because people hold specific notions on how situations influence emotions (Ross, 1989). On the other hand, state affect should also impact trait reports, as a vast body of research on mood-congruent cognition seems to imply (Bower \& Forgas, 2000). Two mechanisms are discussed in this context. First, affective states increase the accessibility of equally valenced memories as affect is part of associative networks (Bower, 1981; Isen, Shalker, Clark, \& Karp, 1978). Being in a good mood, for example, may trigger mainly happy 
memories and this would lead to an overestimation when evaluating trait affect. Second, concurrent feelings serve an informative function for global judgments—when forming a judgment, people draw on their affective experiences as a source of information (Schwarz \& Clore, 2007). The evidence for such effects is broad, including, for example, effects of the weather on reports of life satisfaction or of induced mood on interpersonal attraction and evaluative judgments (Gouaux, 1971; Schwarz \& Clore, 1983; Yeung \& Wyer, 2004).

These insights on confounds between state and trait affect render it very likely that single-occasion evaluations of traits are biased by current states. Two studies with several global wellbeing measures as outcome variables even provide first evidence for such a link (Eid \& Diener, 2004; Eid, Notz, Steyer, \& Schwenkmezger, 1994). Yet, single-occasion evaluations of traits are often used without concern and studies seem to ignore state affect as a rather obvious confounding variable. Hence, this study pursues two goals. First, we demonstrate the contribution of state affect to trait reports of affect with a particularly well-suited study design. Second, we show how this effect is global (e.g., feeling relatively good predicts relatively positive evaluations of trait affect) and specific (those particular facets of affect that are more/less prevalent at the moment are believed to occur more/less often in general).

\section{Empirical Approaches to State-Trait Associations}

Although many studies have been conducted on affect state-trait associations, the majority does not necessarily imply that momentary state affect as occurring in daily life has an impact on global affect ratings. Experimental studies that use mood induction procedures (e.g., sad movies) showed state effects on global judgments of well-being. These findings may not generalize to natural variations of mood in daily life because the latter may be more restricted than variation elicited by induction procedures. Likewise, it is unclear whether systematic main effects of good and bad weather on judgments (Schwarz \& Clore, 1983) generalize to natural variations of mood. Such effects may also be stronger than effects of state affect that reflects a blend of influences, including weather, stress, and diurnal rhythms (Kuppens, Oravecz, \& Tuerlinckx, 2010). Moreover, there are studies reporting effects of natural moods on judgments (e.g., more positive judgments in those individuals reporting better mood), but they mostly measured mood and judgments on single occasions. Therefore, they reflect between-person associations rather than state effects because of trait variance in state affect measures-the "rose-colored glasses" are dispositional rather than situational (Mayer \& Hanson, 1995; Mayer, McCormick, \& Strong, 1995). More generally, findings on high associations between state and trait affect measures at single occasions are uninformative regarding the issue of state effects on trait ratings because the effects are bidirectional—state measures capture trait components and vice versa (Watson \& Clark, 1984).

Taken together, it is highly conceivable that affective states in daily life impact on global evaluations on affect, but the majority of former research related to this issue has shortcomings (e.g., affect was experimentally induced, state effects on judgments were not separable from trait effects). A methodologically adequate empirical approach would require repeated measurements in order to separate state and trait components and to study intraindividual relations. The few studies conducted in this vein have revealed intraindividual relations between natural mood variation and judgments both in patients (depressive symptoms covaried with memory valence; Clark \& Teasdale, 1982) and in a nonclinical sample, where mood predicted the estimation of positive and negative event occurrence (Mayer \& Hanson, 1995). Finally, Eid and colleagues (Eid et al., 1994; Eid \& Diener, 2004) simultaneously assessed momentary and trait affective well-being on multiple occasions and showed that ratings of trait well-being are not independent from momentary mood. Thus, although sparse in number, there is empirical evidence for the highly plausible claim that affective states bias global judgments of well-being. Both theoretical plausibility and empirical evidence seem to have been largely ignored by researchers. In view of the importance of the issue of state effects on global judgments, this study's first goal is to provide convincing evidence that trait affect reports are influenced by momentary mood.

\section{State-Trait Confounds: How Specific Are the Effects?}

As a second goal, and as a new contribution to the literature, we examined how comprehensive the confounding of states and traits is. Ratings of trait affect and state affect result in profiles, that is, the patterns across items belonging to the same construct (e.g., how nervous, upset, and afraid are distributed around the average level of negative affect; Figure 1). Three major profile characteristics are commonly distinguished: its elevation (the mean across scores), its scatter (the standard deviation within a profile), and its shape (the pattern of peaks and valleys; Cattell, 1949; Cronbach \& Gleser, 1953; Furr, 2008). We examined whether state-trait confounds include both, mean levels and the shape of the profile.

The assumptions formulated so far were concerned with elevation, or mean level confounds-concurrent good mood should result in generally higher ratings of trait affect, which we refer to as global or general in the following. Importantly, there are good reasons to also expect a more specific effect, in particular, a confound of state and trait shapes. Trait and state shapes are not necessarily alike. Shapes at the trait level are determined by stable individual characteristics. Individuals differ regarding the probability of experiencing negative and positive emotions, and these differences are related to personality (neuroticism and extraversion; e.g., Costa \& McCrea, 1980). Individuals high in the disposition negative affect are more likely to experience sadness, anger, and fear than those low in negative affect. In factor analytic terms, the levels on the dispositions toward positive and negative emotions (i.e., factor scores of persons on the latent factors) determine the extent to which sadness or anger are experienced. Individuals likely vary regarding their experience of specific facets of affect at the trait level, as should become apparent in their trait shapes (e.g., some persons' high level of neuroticism might be primarily characterized by depressed mood, others' by anxiousness). However, given a general proneness to experience negative and positive states, the trait shapes within individuals should be relatively flat. Findings on relatively high and homogeneous factor loadings on trait negative affect and positive affect factors in factor analytical studies are supportive of this view (e.g., Watson, Clark, \& Tellegen, 1988).

Shapes at the state level should differ from trait shapes because of different causes of variation at the state level. Affect should be 
Rating scale negative affect

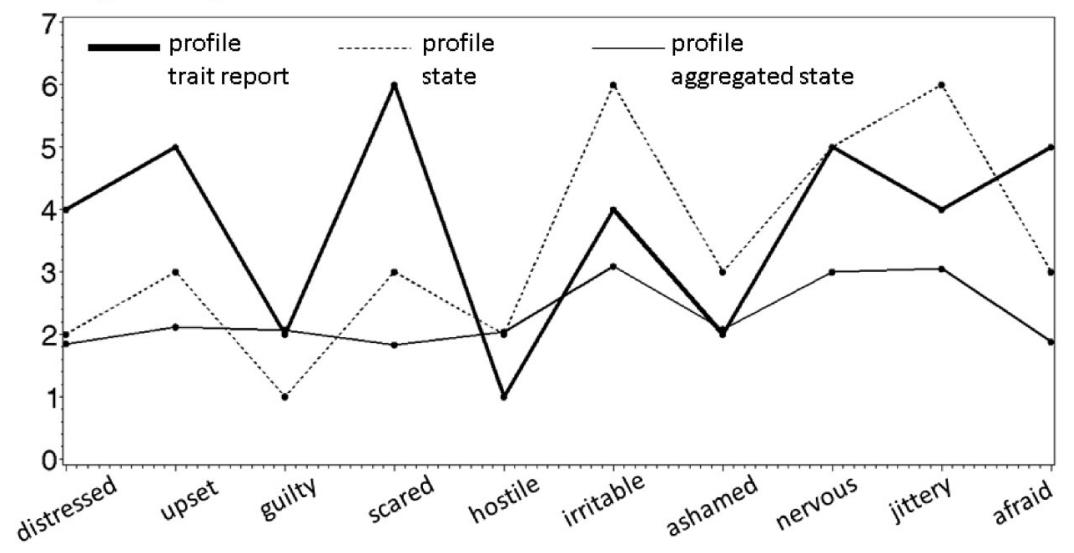

Figure 1. Three profiles of 10 negative affect items of one individual. By profile, we mean the pattern across items belonging to the same construct (e.g., how nervous, upset, and afraid are distributed around the average level of negative affect). In the analyses, we focus on the mean levels (elevation) and shape (peaks and valleys) of the profiles. The three profiles emerged from the assessment of trait report affect and state affect on one occasion at pretest as well as from item aggregation (separately for each item) across 100 subsequent occasions (see Figure 2).

more differentiated at the state than at the trait level because of the specific content of situations. For example, situations potentially eliciting negative affect include a dentist appointment, interpersonal tensions, and public transportation problems, and those probably elicit phenomenologically different affective responses (Zelenski \& Larsen, 2000). Thus, in a specific situation, a person may experience either sadness or anger, independent of his or her average tendency to experience these facets of affect. The more strongly situation-driven shape of state affect should therefore be distinguishable from the more strongly personality-determined shape of trait affect. Recent evidence from experience-sampling studies is supportive of this view. For example, Wilhelm and Schoebi (2007) investigated the structure of affect within and between individuals. They revealed that a two-factor structure best described the between-person structure and a three-factor structure best described the within-structure. Thus, the within-person structure was more differentiated than the between-person structure (see also Brose, Voelkle, Lövdén, Lindenberger, \& Schmiedek, 2013; Vansteelandt, Van Mechelen, \& Nezlek, 2005; Zelenski \& Larsen, 2000). Relatedly, Bleidorn and Peters (2011) revealed a more negative correlation between positive and negative affect and lower internal consistencies at the within- than at the betweenperson level. Both may reflect the situational variations and situation-specific affective responding that are relevant for structural relations at the within-person level.

In summary, theoretical considerations and empirical findings speak for distinguishable affect shapes at the state and trait level. Confounding state and trait measures thus also matters for findings on shapes. The more measures of state and trait affect are confounded, the more similar the shapes of state and trait affect should be. That is, current affect may have a specific effect in the sense that a currently particularly relevant facet is evaluated as more relevant in trait ratings. Such blurring of shapes can thus restrict conclusions about the trait and state structures of affect.

\section{The Present Study}

This study aims to provide direct and strong evidence for the claim that the distinction between state and trait affect, assessed on single occasions, is blurred. Mean level associations and associations of shapes were taken into consideration because we expected that confounds may not only be global, but also specific in the sense that the more relevant aspects of state affect would also be evaluated as more relevant in general. Evidence for a blurred distinction would have important implications for affect assessment and for interpretations of numerous findings in the literature. This study's design (see Figure 2) and its methodological approach provide a unique opportunity to demonstrate linkages between states' and traits' mean levels, but also to go beyond previous research by investigating shape effects. Affect trait reports and

\section{Pretest}

Micro-longitudina/phase

\begin{tabular}{|c|}
\hline retrospective \\
rating of trait- \\
level affect $\rightarrow$ \\
"trait report"
\end{tabular}

\begin{tabular}{c} 
rating of \\
momentary \\
affect $\rightarrow$ \\
"state affect" \\
\hline
\end{tabular}

ratings of momentary affect on 100 days $\rightarrow$ average: , aggregated state“

Figure 2. Study design and measures of state and trait affect in the COGITO study. Affect trait reports and state affect were collected at the same occasion. Subsequently, state affect was measured on 100 occasions in the micro-longitudinal study phase; item-specific averages across the 100 occasions constitute the aggregated state measure. 
state affect were collected on the same occasion. Subsequently, state affect was measured on 100 occasions in the microlongitudinal study phase. Hence, we were able to form an aggregated state measure (i.e., the average across 100 occasions) which represents individual differences in the experience of affective states. By means of this aggregated state measure we were able to control for individual differences in the state measure when determining the contribution of state affect to trait reports, which is essential in view of trait components in the state measure (see above). Shape associations between traits and states were estimated by a specific use of multilevel modeling, as will be explained below.

\section{Method}

\section{Sample and Procedure}

The COGITO study is a microlongitudinal study in which 101 younger and 103 older adults participated in about 120 days of assessments of cognitive performance and daily life experiences (Schmiedek, Lövdén, \& Lindenberger, 2010). The sample of the current investigation consisted of 90 younger (20-31 years) and 90 older (65-80 years) adults from this study. The state measure was added shortly after data collection started and was, therefore, only available for this smaller number of participants. Incentives varied between 1.450 and 1.950 Euro, depending on the pace of study completion. All sessions were carried out from Monday to Saturday between 8:00 and 19:00 h. Tasks and questionnaires were computerized. The total number of sessions per person in the microlongitudinal study phase (see Figure 2) ranged from 87 to $107(M=101)$. Information on state affect is available for all these sessions. More information on the COGITO study is provided in Schmiedek, Lövdén, and Lindenberger (2010).

\section{Measures}

Trait affect. Evaluations of trait positive and negative affect (PA and NA) were assessed with 20 items of the Positive and Negative Affect Schedule (PANAS; Watson, Clark, \& Tellegen, 1988). At pretest, participants rated how often they had experienced each facet of affect over the last year. An 8-point answering scale was used $(0=$ not at all to $7=$ very often $)$. We henceforth refer to this measure as trait report.

State affect and aggregated state affect. The same 20 PANAS items were used to assess state PA and NA. At all study occasions, participants rated their momentary affect on an 8-point scale $(0=$ does not apply at all to $7=$ applies very well). The responses to the state measure given on the same day on which the trait report measure was administered were particularly relevant for the analyses. They are henceforth referred to as state affect. In addition, the responses to the state measure across the 100-days phase were aggregated by averaging the responses of each participant separately for each item. The resulting measure is henceforth referred to as aggregated state and describes individual differences in the averaged state. Because the states were averaged across 100 state reports, they are highly reliable estimates. On the very first occasion of the study, the questionnaire was administered with paper and pencil to familiarize participants with the questions.

\section{Statistical Analyses}

The multilevel model. The research questions were addressed in a multilevel modeling framework that can take account of the nested data structure and testing associations at multiple levels of the data (e.g., Snijders \& Bosker, 1999). We expected trait affect to be associated with state affect, and tested this hypothesis separately for positive affect (PA) and negative affect (NA). The analytical approach is illustrated in Figure 3. Two levels were considered (Figure 3, upper part; NA serves as an example here). The different items measuring NA were Level-1 variables. These are the repeated measurements that are nested within persons, at Level 2 of the multilevel model. This type of multilevel model belongs to the group of multivariate multilevel models (Snijders \& Bosker, 1999; "multivariate" refers to the fact that the criterion, trait affect, was operationalized with multiple dependent variables, i.e., the affect items). At first glance, one may regard the COGITO study's data structure in terms of days rather than items nested within individuals. However, the measures used in this particular investigation were not repeated across days. Trait affect was measured once at pretest, state affect was measured once on the same day, and we used one aggregate across 100 days.

The criterion of the multilevel model is trait affect, in particular, a vector of item-specific scores (Figure 3, lower part). There were two Level-2 predictors in this model (person-level predictors): (a) the mean level across items of the state measure and (b) the mean level across items of the aggregated state measure. With these Level-2 predictors, we tested whether individuals with higher mean levels across items on the state measure had higher mean levels in the criterion. There were also two Level-1 predictors in this model (item-level predictors): the item vectors of (a) the state measure and (b) the aggregated state measure. With these Level-1 predictors, we tested whether the deviation of item-specific scores in the criterion (i.e., the shape of the profile) was similar to the deviations of item-specific scores of the aggregated state measure and of the state measure. Including the aggregated state measure implies control for stable components in the state measure. If our assumption that trait affect is infiltrated by state affect is correct, we should find significant associations between trait reports and state affect, over and above the associations between trait reports and aggregated states.

The following statistical model was used to test our assumptions (an equivalent model was tested for PA):

Level-1 Model

$$
\begin{aligned}
& \text { NA Trait Report } i j=\beta_{0 i}+\beta_{1 i}\left(\text { NA State Shape }{ }_{i j}\right. \text { ) } \\
& +\beta_{2 i}(\text { NA Agg State Shape } i j)+e_{i j}
\end{aligned}
$$

Level-2 Model

$$
\begin{aligned}
& \beta_{0 i}=\gamma_{00}+\gamma_{01}(\text { NA State })+\gamma_{02}(\text { NA Agg State })+u_{0 i} \\
& \beta_{1 i}=\gamma_{10}+u_{1 i} \\
& \beta_{2 i}=\gamma_{20}+u_{2 i} .
\end{aligned}
$$

In these equations, the criterion NA Trait Report of person $i$ on item $j$ is a function of the intercept, $\boldsymbol{\beta}_{O i}$. This intercept of person $i$ corresponds to the mean of trait report NA across all items. It is further qualified at Level 2. Here, the intercept is predicted by the mean across all items of state NA, $\boldsymbol{\gamma}_{01}$, and by the mean across all 
Nested data structure

Person 1
Person 2
Level-2

180 persons

Level-1

10 items

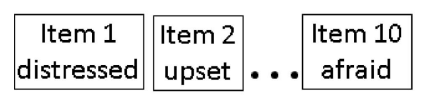

Illustration of data
Criterion

Trait report

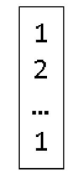

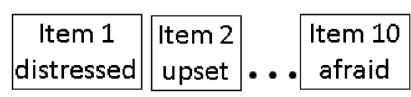

\section{Predictors}

Level-2 Level-1 Level-2 Level-1

Mean S ShapeS Mean AS Shape AS
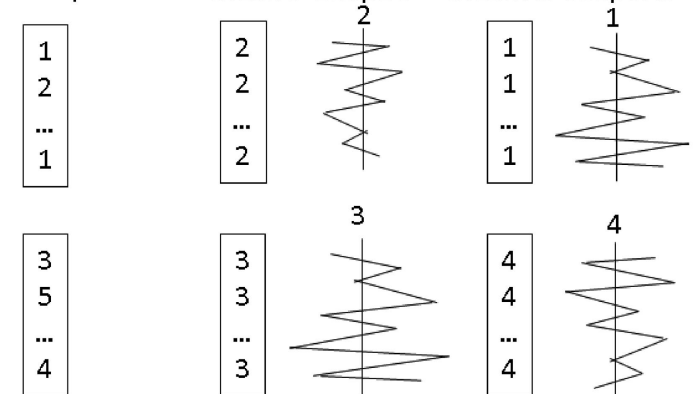
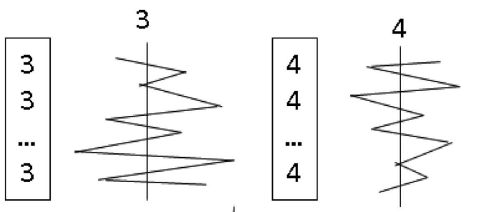

measured on the same pretest occasion 100-occasion aggregate

Figure 3. Illustration of the nested data structure and of the statistical model that was tested: A two-level model with items nested within individuals and person- and item-level predictors; two separate models were conducted for PA and NA; $\mathrm{S}=$ state affect, $\mathrm{AS}=$ aggregated state affect.

items of aggregated (agg) state NA, $\boldsymbol{\gamma}_{02}$. The first predictor, NA State, reflects the hypothesis that the mean of people's trait reports (i.e., the elevation of the trait profile) is related to the mean of how they feel at the specific moment of evaluating their traits (i.e., the elevation of the state profile). The second predictor, NA Agg State, was included to control for stable components of the NA state measure and because of the assumption that the mean of people's trait reports is related to the mean of their actual experiences (i.e., the elevation of the aggregated state profile). These Level-2 predictor variables were grand-mean centered (the sample mean was subtracted from the individuals' scores). The random effect $\mathrm{u}_{\mathrm{O} i}$ in the Level-2 equation reflects individual differences in the mean value of trait report affect across items.

In the equations above, NA Trait Report is furthermore predicted by the Level-1 variables, NA State Shape, $\boldsymbol{\beta}_{1 i}$, and NA Agg State Shape, $\boldsymbol{\beta}_{2 i}$. These represent the shape of the state measure and the shape of the aggregated state measure. Including these predictors makes it possible to test whether the shape of trait reports is related to the shape of state reports on the same day after controlling for the shape of the aggregated state. As noted above, trait affect entered the analyses as a vector of item-specific scores. Thus, the Level-1 predictors make it possible to test whether the deviations of the items $j$ from the trait report's mean across items are correlated with the deviations of the items $j$ from the mean across items of the aggregated state measure, $\boldsymbol{\beta}_{1 i}$, and the deviations of the items $j$ from the mean across the items of the state measure, $\boldsymbol{\beta}_{2 i}$. These Level-1 predictor variables were person-mean centered (i.e., deviations from this person's mean). In the Level-2 equations of $\boldsymbol{\beta}_{1 i}$ and $\boldsymbol{\beta}_{2 i}$, the terms $\mathrm{u}_{1 i}$ and $\mathrm{u}_{2 i}$ are added, implying that the two slopes are random - the strength of the association between the trait report shape and the aggregated state and state shape are allowed to vary across persons. The parameter $\mathrm{e}_{i j}$ denotes residual variance (variance in the criterion that cannot be explained by the predictors). All analyses were conducted using SAS PROC MIXED. The residual variance was modeled using a banded main diagonal structure (the UN(1) covariance function in the REPEATED statement), so that residual variance was estimated separately for each item.

\section{Results}

The results supported expectations that trait reports on single occasions are influenced by the affective state on the assessment day (see Table 1). Mean levels in state NA predicted mean levels in trait report NA, and mean levels in state PA predicted mean levels in trait report PA. This can be inferred from the significant positive regression coefficients State mean level in Table 1. Thus, when reporting trait PA, individuals who were in a better mood on the pretest day provided higher ratings of how they had felt in general over the last year. Likewise, when reporting trait NA, individuals who were in a worse mood on the pretest day provided higher ratings of trait NA over the last year. The inclusion of the predictor Aggregated State mean level was the statistical control for stable individual differences in the state measure, which rules out that the associations of the trait report and the corresponding current state are due to stable individual differences in the state measure. The additional predictors in the model, State shape and Aggregated State shape predicted the shape of trait report items (i.e., which particular facets of affect were experienced more or less than the mean across the items). The significant positive 
Table 1

Prediction of Trait Report Affect by State and Aggregated State Affect (Mean Level and Shape)

\begin{tabular}{|c|c|c|c|c|}
\hline & \multicolumn{2}{|c|}{ Negative affect } & \multicolumn{2}{|c|}{ Positive affect } \\
\hline & Estimate & $S E$ & Estimate & $S E$ \\
\hline \multicolumn{5}{|l|}{ Fixed effects } \\
\hline Intercept & $2.43^{*}$ & 0.08 & $4.59^{*}$ & 0.06 \\
\hline Aggregated state mean level & $0.64 *$ & 0.12 & $0.16^{*}$ & 0.05 \\
\hline Aggregated state shape & $1.17^{*}$ & 0.11 & $0.37^{*}$ & 0.05 \\
\hline State mean level & $0.32^{*}$ & 0.10 & $0.28^{*}$ & 0.06 \\
\hline State shape & $0.22 *$ & 0.04 & $0.21^{*}$ & 0.02 \\
\hline \multicolumn{5}{|l|}{ Variance components } \\
\hline Intercept & $1.01^{*}$ & 0.13 & $0.54^{*}$ & 0.07 \\
\hline Slope (shape aggregated state) & $0.65^{*}$ & 0.24 & $0.16^{*}$ & 0.05 \\
\hline Slope (shape state) & 0.03 & 0.02 & $0.02^{*}$ & 0.01 \\
\hline \multicolumn{5}{|l|}{ Residual variances } \\
\hline distressed/enthusiastic & $3.61^{*}$ & 0.42 & $1.98^{*}$ & 0.23 \\
\hline upset/excited & $3.89^{*}$ & 0.44 & $2.16^{*}$ & 0.24 \\
\hline guilty/strong & $1.16^{*}$ & 0.15 & $1.11^{*}$ & 0.13 \\
\hline scared/interested & $1.29^{*}$ & 0.16 & $0.85^{*}$ & 0.11 \\
\hline hostile/proud & $1.95^{*}$ & 0.23 & $1.08^{*}$ & 0.16 \\
\hline irritable/alert & $1.93^{*}$ & 0.23 & $0.85^{*}$ & 0.11 \\
\hline ashamed/inspired & $1.47^{*}$ & 0.18 & $0.74^{*}$ & 0.10 \\
\hline nervous/determined & $1.72^{*}$ & 0.22 & $1.31^{*}$ & 0.15 \\
\hline jittery/attentive & $1.44^{*}$ & 0.19 & $0.58^{*}$ & 0.07 \\
\hline afraid/active & $0.86^{*}$ & 0.12 & $0.72^{*}$ & 0.09 \\
\hline
\end{tabular}

" $p<.05$.

coefficients in Table 1 reveal that the shapes of state PA and NA as well as shapes of aggregated state PA and NA predicted trait report shapes of PA and NA. That is, the pattern of how NA state items varied around the mean levels of state NA predicted how NA trait report items varied around the mean level of NA trait reports. Likewise, the pattern of how PA state items varied around the mean levels of state PA predicted how PA trait report items varied around the mean level of PA trait reports. The simultaneous inclusion of Aggregated State shape and State shape means that after controlling for trait-like aspects in the state measure, the shape of the state measure has unique predictive variance on the trait report shape. That is, the shape of trait report affect is more similar to the shape of momentary affect than to be expected on the basis of stable components in the state measure, and this speaks for a confounding of state and trait report shapes.

To determine the proportion of variance in trait reports uniquely explainable by state affect, we calculated the increase in predicted trait report variance when including state affect in the analysis subsequent to aggregated states (i.e., state affect's unique effect; Figure 4). Multilevel models provide estimates of residual variance components at the different levels, the so called Pseudo- $R^{2}$ statistic (Snijders \& Bosker, 1999). Including meaningful Level-1 predictors usually reduces residual variance at Level 1 , and including meaningful Level-2 predictors usually reduces variance at Level 2 (variance in the intercept). Running successive models thus allows determination of the change in Pseudo- $R^{2}$, similar to that of the change in $R^{2}$ in multiple regression analyses. These analyses were done separately for the mean levels and for the shapes (at Level 1 and Level 2). Mean levels of state affect uniquely predicted mean levels of trait reports, and shapes of state affect uniquely predicted shapes of trait affect. Figure 4 also shows that substantial portions of the predictive variance between state and aggregated state affect are shared, suggesting that dispositions and everyday experiences are linked.

The proportions of variance explained by states depicted in Figure 4 refer to the total amount of variance in the mean level and shape of the predictor. The proportion of variance explained by states can also be seen in relation to the total amount of explained variance. Relative to the total amount of variance predicted by states and aggregated states, state affect explained between $14 \%$ $38 \%$, NA mean: $14 \%$, NA shape: $38 \%$, PA mean: $26 \%$, PA shape: $29 \%$. Thus, a considerable amount of explained variance in trait reports was uniquely predicted by how participants felt when evaluations were made.

\section{Discussion}

We showed that the distinction between common measures of state and trait affect is blurred. Current affective states predict trait reports, that is, how people evaluated their affective experiences in general. Moreover, state reports at single occasions capture individual differences in affective experiences. The identified confounds encompass global and specific effects: Not only does feeling better on a particular occasion lead to above-average judgments of trait affect; beyond this influence, dominating aspects of current state affect are also judged as being more relevant in general. That is, in addition to mean level effects that were also identified in previous research, we showed effects of states' shapes on trait reports' shapes. The effect of the specific (shape) component indicates that current affect influences trait ratings in a surprisingly differentiated way. It thus seems that momentary affect

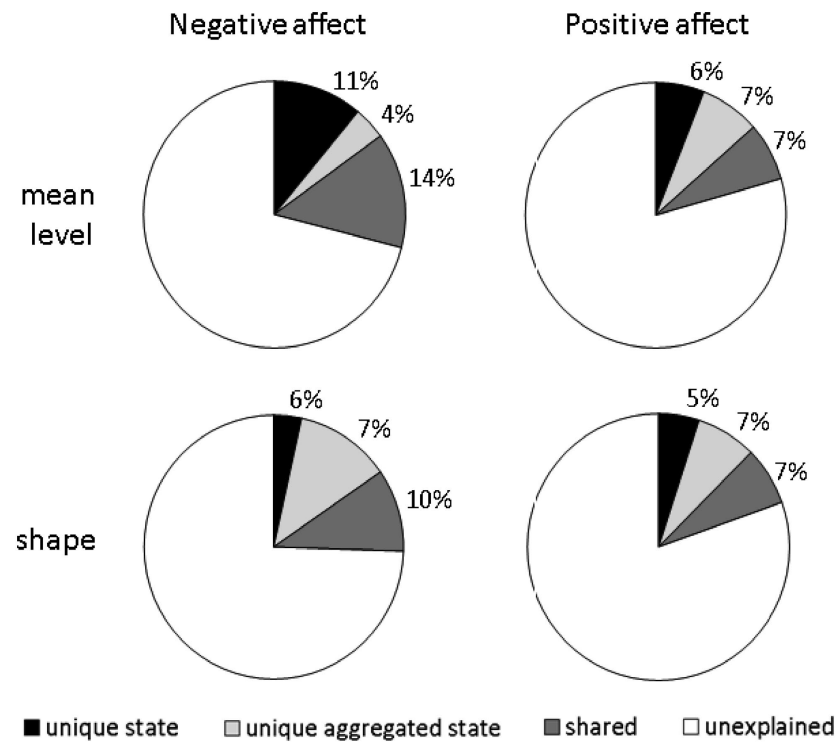

Figure 4. Results from multilevel modeling: Explained variance in trait report negative and positive affect at pretest, separately for mean levels and profiles; predictors: state and aggregated state affect; unique state refers to the variance in trait affect that was predicted uniquely by state affect in multiple regression analysis that included state and aggregated state as predictors; unique aggregated state affect refers to the variance in trait affect was predicted uniquely by the aggregated state measure, and shared refers to the predictive variance that was shared among the two predictors in the same analysis. 
not only provides cues for peoples' global evaluations of wellbeing - it not only functions like rose-colored glasses - but it also influences their complex image of their personal affective systems.

These findings concur with theoretical notions on the link between affective states and judgments: both with the idea that feelings inform global judgments (Schwarz \& Clore, 2007) and with the affect priming model, which proposes the facilitated access to mood-congruent material in memory (Bower, 1981; Isen et al., 1978). Moreover, these findings corroborate findings of two studies revealing naturally occurring state effects on trait affect (Eid \& Diener, 2004; Eid et al., 1994). The design and analytical procedures of this study render it highly unlikely that the observed effects of state affect on trait report reflect trait-like components in the state measure because it was possible to adjust for these components by means of the aggregated state measure.

It is highly surprising that prior theoretical and empirical support for confounds of state and trait affect measures has not attracted sufficient attention to question the validity of existing trait affect assessment routines-single-occasion assessments of trait affect are still the norm. Ideally, the strong evidence on the blurred distinction between state and trait measures of affect provided by this study will stimulate a change in measurement procedures.

\section{Implications of Findings}

Our findings have numerous implications. Most importantly, measures of trait affect (e.g., PANAS), if administered on a single occasion, are nonoptimal to assess traits because they are confounded by states. The common practice of measuring affect once using a trait measure may bias results as follows: (a) If the affect measure is the criterion variable in, for example, a study on long-term effects of traumatic events, the true association between events and affect may be underestimated because of trait report variance that is due to concurrent influences. (b) Concurrent associations between trait affect and related variables (e.g., chronic stress) may be overestimated if the state influences the ratings on both scales similarly. Currently feeling sad may result in evaluating global affect and chronic stress level as more negative than when feeling happy. (c) Intraindividual trajectories of trait-level affect spanning across critical life periods such as terminal decline cannot be predicted well because of unwanted state variance in the trait measure. (d) Evaluations of interventions may come to the wrong conclusions if systematic state variance impacts on trait ratings (e.g., if situational factors differentially influence different experimental groups, that is, in terms of history effects as threats to internal validity; cf. Shadish, Cook, \& Campbell, 2002). (e) Finally, and regarding the shape effect, findings on the underlying structure of affect may be biased if variations on trait measures also reflect state variation. For example, the PANAS has often been applied across age groups, normal and clinical populations, and countries to ascertain its construct validity (Leue \& Beauducel, 2011). If the measures confound state and trait, insights about affect structure are not clearly attributable to state or trait, but represent a mixture of both. Moreover, the dimensionality of trait-level affect may be overestimated if the contribution of state affect is large because the dimensionality of state affect variability is probably higher than that of traits (Zelenski \& Larsen, 2000).
Analogous arguments can be made against measuring states on single occasions. The contribution of trait to state affect cannot be determined if state affect is measured on single occasions, and associations between state affect and other variables may be underor overestimated.

The present results and theoretical considerations highlight the need for study designs and statistical methods that overcome the shortcomings of one-shot assessments. Central to more valid designs is the repeated observation of the phenomena of interest and the inclusion of trait and state measures that provide complementary information. This conclusion is compatible with suggestions in trait research to use repeated measurements to isolate stable from transient variance (Anusic, Lucas, \& Donnellan, 2012; Chmielewski \& Watson, 2009). Latent state-trait models (e.g., Steyer, Schmitt, \& Eid, 1999) can be used to model state and trait components of repeated observations. Moreover, aggregating information across occasions-trait or state reports-reduces state variance components (e.g., Bolger, Davis, \& Rafaeli, 2003).

\section{Limitations and Future Directions}

Some of this study's findings require elaboration and some procedural aspects could be reconsidered in future studies. First, we report exact percentages of bias (Figure 4; e.g., the state effect on mean level trait ratings is $11 \%$ ). These values will certainly vary across studies, depending on study procedures such as the nature of the measures or on the population under study. For example, this study used the PANAS, an instrument that only samples high arousal affective states. Very likely, the shape effects would have been stronger if a larger range of states had been measured because this would allow more precise capture of phenomenologically distinct affective experiences. Relatedly, this study measured trait affect with a frequency and state affect with an intensity measure, respectively. This may have led to an underestimation of the shared variance between state, aggregated state, and trait. On the other hand, as it is difficult to determine the frequency of affective states over the past year, current intensity was potentially a particularly good heuristic for the global evaluation. Finally, we did not account for measurement error as we modeled associations at the manifest level. Thereby, we may have even underestimated the influence of state on trait affect. Together, the scope of the bias will vary depending on the range of states under investigation, on the type of measure (frequency or intensity), and on analytical procedures.

The extent to which state affect biases affective trait reports is most likely also a function of contextual variation within and across studies. Whether judgments are based on a precise analysis of circumstances or whether they are more global, reflecting on a current overall feeling depends on how people feel at a specific moment (Gable \& Harmon-Jones, 2010; Isen, Daubman, \& Nowicki, 1987). These two processing modes, analytic and heuristic, are differentially associated with negative and positive affect. Whereas discomfort is accompanied by more careful thinking, feeling happy signals the absence of threats-effortful thinking is not required and judgments can be based on simple heuristics (Schwarz, 1990). Trait ratings should, therefore, be less biased when negative affect is enhanced. For example, measuring trait affect in summer in high school students who have just graduated may result in highly heuristic and positively biased evaluations of 
trait affect because the students are in a happy state. Measuring trait affect again in these subjects 0.5 years later, in winter, just before they are about to take some exams at college would probably evince lower ratings of trait affect. Observing change in trait affect here may simply reflect the difference between a positively biased versus realistic evaluation of one's global affectivity.

Third, there are multiple ways to determine the similarity of profiles (e.g., Cronbach \& Gleser, 1953). An interesting recent line of research distinguishes between the normativeness (the degree to which a profile reflects an average profile) and the distinctiveness of a profile (the deviation of a profile from the normative profile; Furr, 2008). This distinction reveals another approach to examining the similarity between state and trait profiles on a specific occasion. Repeated sampling of the trait report and state affect would enable the calculation of the trait and state profile distinctiveness at each occasion. The within-day correlation of these distinctive profiles would then also reveal state effects on trait reports. In view of the lack of repeated trait report measurements in the present investigation, this remains a task for future research.

\section{Conclusion}

The present results demonstrate that the exclusive reliance on a one-shot assessment of trait report is nonoptimal to capture individual differences in trait affect. This is not surprising-there are limitations to what people can tell researchers about themselves on any particular scale at any given occasion, and we have theoretical insights about these limitations, and about the interconnections among trait reports, states, and aggregated states. Yet it is surprising that single-occasion assessments of trait affect are still the norm in psychological, sociological, and medical research. Given theoretical knowledge, prior empirical findings, and this study's direct and strong evidence on state-trait confounds of mean level and also shapes of affective experiences, we suggest it is high time to use designs and statistical models that articulate the various levels and facets of subjective affective experiences, and investigate their shared and unique influences on real-life outcomes.

\section{References}

Anusic, I., Lucas, R. E., \& Donnellan, M. B. (2012). Dependability of personality, life satisfaction, and affect in short-term longitudinal data. Journal of Personality, 80, 33-58. doi:10.1111/j.1467-6494.2011 .00714.x

Barrett, L. F. (1997). The relationships among momentary emotion experiences, personality descriptions, and retrospective ratings of emotion. Personality and Social Psychology Bulletin, 23, 1100-1110. doi: 10.1177/01461672972310010

Bleidorn, W., \& Peters, A. L. (2011). A multilevel multitrait-multimethod analysis of self- and peer-reported daily affective experiences. European Journal of Personality, 25, 398-408. doi:10.1002/per.804

Bolger, N., Davis, A., \& Rafaeli, E. (2003). Diary methods: Capturing life as it is lived. Annual Review of Psychology, 54, 579-616. doi:10.1146/ annurev.psych.54.101601.145030

Bower, G. H. (1981). Mood and memory. American Psychologist, 36, $129-148$.

Bower, G. H., \& Forgas, J. P. (2000). Affect, memory, and social cognition. In E. Eich, J. F. Kihlstrom, \& G. H. Bower (Eds.), Cognition and emotion (pp. 87-168). New York, NY: Oxford University Press.

Brose, A., Voelkle, M. C., Lövdén, M., Lindenberger, U., \& Schmiedek, F. (2013). Investigating the divergence of between-person and within- person affect structures: A new line of inquiry for research on personality. Manuscript submitted for publication.

Carroll, J. M., Yik, M. S., Russell, J. A., \& Barrett, L. F. (1999). On the psychometric principles of affect. Review of General Psychology, 3, 14-22. doi:10.1037/1089-2680.3.1.14

Cattell, R. B. (1949). r(p) and other coefficients of pattern similarity. Psychometrika, 14, 279-298. doi:10.1007/BF02289193

Chmielewski, M., \& Watson, D. (2009). What is being assessed and why it matters: The impact of transient error on trait research. Journal of Personality and Social Psychology, 97, 186-202. doi:10.1037/ A0015618

Clark, D. M., \& Teasdale, J. D. (1982). Diurnal variation in clinical depression and accessibility of memories of positive and negative experiences. Journal of Abnormal Psychology, 91, 87-95. doi:10.1037/ 0021-843X.91.2.87

Clark, L. A., \& Watson, D. (1991). Tripartite model of anxiety and depression. Psychometric evidence and taxonomic implications. Journal of Abnormal Psychology, 100, 316-336. doi:10.1037/0021-843X.100.3 .316

Costa, P. T., \& McCrae, R. R. (1980). Influence of extraversion and neuroticism on subjective well-being: Happy and unhappy people. Journal of Personality and Social Psychology, 38, 668-678. doi:10.1037/ 0022-3514.38.4.668

Cronbach, L. J., \& Gleser, G. C. (1953). Assessing similarity between profiles. Psychological Bulletin, 50, 456-473. doi:10.1037/h0057173

Eid, M., \& Diener, E. (2004). Global judgments of subjective well-being: Situational variability and long-term stability. Social Indicators Research, 65, 245-277. doi:10.1023/B:SOCI.0000003801.89195.bc

Eid, M., Notz, P., Steyer, R., \& Schwenkmezger, P. (1994). Validating scales for the assessment of mood level and variability by latent statetrait analyses. Personality and Individual Differences, 16, 63-76. doi: 10.1016/0191-8869(94)90111-2

Fredrickson, B. L. (2000). Extracting meaning from past affective experiences: The importance of peaks, ends, and specific emotions. Cognition and Emotion, 14, 577-606. doi:10.1080/026999300402808

Furr, R. M. (2008). A framework for profile similarity: Integrating similarity, normativeness, and distinctiveness. Journal of Personality, 76, 1267-1316. doi:10.1111/j.1467-6494.2008.00521.x

Gable, P., \& Harmon-Jones, E. (2010). The motivational dimensional model of affect: Implications for breadth of attention, memory, and cognitive categorisation. Cognition \& Emotion, 24, 322-337. doi: Pii 919392031

Gouaux, C. (1971). Induced affective states and interpersonal attraction. Journal of Personality and Social Psychology, 20, 37-43. doi:10.1037/ h0031697

Gross, J. J., Sutton, S. K., \& Ketelaar, T. (1998). Relations between affect and personality: Support for the affect-level and affective-reactivity views. Interaction/Stress, 24, 279-288.

Isen, A. M., Daubman, K. A., \& Nowicki, G. P. (1987). Positive affect facilitates creative problem solving. Journal of Personality and Social Psychology, 52, 1122-1131. doi:10.1037/0022-3514.52.6.1122

Isen, A. M., Shalker, T., Clark, M., \& Karp, L. (1978). Affect, accessibility of material in memory, and behavior: A cognitive loop? Journal of Personality and Social Psychology, 36, 1-12. doi:10.1037/0022-3514 .36 .1 .1

Kuppens, P., Oravecz, Z., \& Tuerlinckx, F. (2010). Feelings change: Accounting for individual differences in the temporal dynamics of affect. Journal of Personality and Social Psychology, 99, 1042-1060. doi:10.1037/a0020962

Lazarus, R. S. (1999). Stress and emotion: A new synthesis. New York, NY: Springer.

Leue, A., \& Beauducel, A. (2011). The PANAS structure revisited: On the validity of a bifactor model in community and forensic samples. Psychological Assessment, 23, 215-225. doi:10.1037/a0021400 
Mayer, J. D., \& Hanson, E. (1995). Mood-congruent judgment over time. Personality and Social Psychology Bulletin, 21, 237-244. doi:10.1177/ 0146167295213005

Mayer, J. D., McCormick, L. J., \& Strong, S. E. (1995). Mood-congruent memory and natural mood: New evidence. Personality and Social Psychology Bulletin, 21, 736-746. doi:10.1177/0146167295217008

Robinson, M. D., \& Clore, G. L. (2002). Belief and feeling: Evidence for an accessibility model of emotional self-report. Psychological Bulletin, 128, 934-960. doi:10.1037/0033-2909.128.6.934

Ross, M. (1989). Relation of implicit theories to the construction of personal histories. Psychological Review, 96, 341-357. doi:10.1037/ 0033-295X.96.2.341

Schmiedek, F., Lövdén, M., \& Lindenberger, U. (2010). Cognitive enrichment in old age. GeroPsych, 23, 59-67.

Schwarz, N. (1990). Feelings as information: Informational and motivational functions of affective states. In R. M. Sorrentino \& E. T. Higgins (Eds.), Handbook of motivation and cognition: Cognitive foundations of social psychology (Vol. 2, pp. 527-561). New York, NY: Guilford.

Schwarz, N. (2007). Retrospective and concurrent self-reports: The rationale for real-time data capture. In A. A. Stone, S. S. Shiffman, A. Atienza, \& L. Nebeling (Eds.), The science of real-time data capture: Self-reports in health research (pp. 11-26). New York, NY: Oxford University Press.

Schwarz, N., \& Clore, G. L. (1983). Mood, misattribution, and judgments of well-being: Informative and directive functions of affective states. Journal of Personality and Social Psychology, 45, 513-523. doi:10 $.1037 / / 0022-3514.45 .3 .513$

Schwarz, N., \& Clore, G. L. (2007). Feelings and phenomenal experiences. In E. T. Higgins \& A. Kruglanski (Eds.), Social psychology: Handbook of basic principles (2nd ed., pp. 385-407). New York, NY: Guilford.

Scollon, C. N., Howard, A. H., Caldwell, A. E., \& Ito, S. (2009). The role of ideal affect in the experience and memory of emotions. Journal of Happiness Studies, 10, 257-269. doi:10.1007/s10902-007-9079-9

Shadish, W., Cook, T., \& Campbell, D. (2002). Experimental and quasiexperimental designs for generalized causal inference. Boston, MA: Houghton Mifflin.

Snijders, T., \& Bosker, R. (1999). Multilevel analysis: An introduction to basic and advanced multilevel modeling. London: Sage.
Steyer, R., Schmitt, M., \& Eid, M. (1999). Latent state-trait theory and research in personality and individual differences. European Journal of Personality, 13, 389-408. doi:10.1002/(SICI)1099-0984(199909/10)13: 5<389::AID-PER361>3.0.CO;2-A

Stone, A. A., Schwartz, J. E., Broderick, J. E., \& Deaton, A. (2010). A snapshot of the age distribution of psychological well-being in the United States. Proceedings of the National Academy of Sciences, USA, 107, 9985-9990. doi:10.1073/pnas.1003744107

Vansteelandt, K., Van Mechelen, I., \& Nezlek, J. B. (2005). The cooccurrence of emotions in daily life: A multilevel approach. Journal of Research in Personality, 39, 325-335. doi:10.1016/j.jrp.2004.05.006

Watson, D., \& Clark, L. A. (1984). Negative affectivity: The disposition to experience aversive emotional states. Psychological Bulletin, 96, 465490. doi:10.1037/0033-2909.96.3.465

Watson, D., Clark, L. A., \& Tellegen, A. (1988). Development and validation of brief measures of positive and negative affect: The PANAS scales. Journal of Personality and Social Psychology, 54, 1063-1070. doi:10.1037/0022-3514.54.6.1063

Wilhelm, P., \& Schoebi, D. (2007). Assessing mood in daily life. Structural validity, sensitivity to change, and reliability of a short scale to measure three basic dimensions of mood European Journal of Psychological Assessment, 23, 258-267. doi:10.1027/1015-5759.23.4.258

Wilson, T. D., \& Dunn, E. W. (2004). Self-knowledge: Its limits, value, and potential for improvement. Annual Review of Psychology, 55, 493518. doi:10.1146/annurev.psych.55.090902.141954

Yeung, C. W. M., \& Wyer, R. S. (2004). Affect, appraisal, and consumer judgment. Journal of Consumer Research, 31, 412-424. doi:10.1086/ 422119

Zelenski, J. M., \& Larsen, R. J. (2000). The distribution of basic emotions in everyday life: A state and trait perspective from experience sampling data. Journal of Research in Personality, 34, 178-197. doi:10.1006/jrpe .1999 .2275

Received August 22, 2012

Revision received February 1, 2013

Accepted February 19, 2013 